\title{
Perspectiva práctica del humanismo: teatro social experimentado por estudiantes universitarios del Centro de Estudios Generales
}

\section{Practical perspective of humanism: a theatrical experience in the sensitive body of the university student}

Julio Barquero Alfaro Centro de Estudios Generales Universidad Nacional Heredia, Costa Rica julio.barquero.alfaro@una.cr

\section{Resumen}

El objetivo de este artículo se centra en la valoración del curso académico Teatro del oprimido: una perspectiva práctica del humanismo como un espacio artístico y crítico brindado a la población estudiantil del Centro de Estudios Generales. Dicha propuesta se acompaña de la posición teórica de Augusto Boal y de elementos específicos de Carlos Taibo y Armand Mattelart y la experimentación práctica del propio curso y sus alcances; se analiza el proceso académico, su importancia y necesidad en la superación de la literalidad y la pasividad del futuro profesional universitario, con miras hacia el compromiso social, que es inherente a la formación. La experiencia vivida por el grupo de participantes transforma

la concepción convencional del teatro, al ser esta un eje generador de movilización social que promueve la capacidad de 
conciencia crítica individual y colectiva en la comunidad universitaria, como instrumento expresivo-reflexivo, organizacional y recreativo, que estimula la participación ciudadana.

Palabras claves: teatro del oprimido, cuerpo, opresión, globalización.

\begin{abstract}
The purpose of this article focuses on the assessment of the academic year Theatre of the Oppressed: A Practical Perspective of Humanism as an art critic and space given to the student population Geenerales Studies Center. The proposal is accompanied by the theoretical position of Augusto Boal and specific elements of Carlos Taibo and Mattelart experimentation and practice their own course and scope, the academic process is analyzed, its importance and necessity in overcoming literalism and passivity university professional future, with a view of the inherent social commitment to training. The experience of the participant group transforms the conventional conception of theater, this being a generator shaft that promotes social mobilization capacity of individual and collective critical consciousness in the university community, as an expressive instrumentreflective, organizational and recreation, which encourages citizen participation.
\end{abstract}

Keywords: theatre of the oppressed, body, oppression, globalization.

"Una oportunidad en la que la población universitaria conoció el teatro desde un libro, un vídeo, una mirada, otro cuerpo, su propio cuerpo."

Julio Barquero

\title{
Introducción a la experiencia
}

$\mathrm{L}$ a experiencia compartida por medio de este artículo pretende evidenciar la necesidad que existe en la academia universitaria de brindar nuevas formas de participación estudiantil por medio de las artes; al mismo tiempo, marca la relevancia entre el enfoque humanista, fomentado en el Centro de Estudios Generales de la Universidad Nacional, y la capacidad creadora de la población estudiantil, a través de procesos humanísticos generadores de acción social. Dicho planteamiento se apoya en varios componentes teóricos que enriquecen su análisis, como son la concepción de los movimientos sociales, según Carlos Taibo, los fundamentos del Teatro del Oprimido del director Augusto Boal y los cuestionamientos sobre la globalización de la cultura, que desarrolla el sociólogo Armand Mattelart desde el enfoque de la comunicación. 
El curso Teatro del oprimido: una perspectiva práctica del humanismo se desarrolló en el I ciclo del 2013, según el calendario universitario. Es un curso perteneciente al área de Artes y tuvo como principal objetivo desarrollar sensibilidad crítica y empoderamiento social en el estudiantado universitario, por medio de recursos teatrales que la misma corriente brinda con el fin de analizar las relaciones humanas y sus mecanismos de poder, inmersos en la sociedad, en pro de la transformación de las problemáticas sociales.

La corriente de Teatro del Oprimido está compuesta por una serie de técnicas que involucran la participación activa, la disponibilidad emocional, la capacidad lúdica y crítica y los referentes de vida relacionados con el concepto de opresión social. Por lo tanto, realizar este curso en el marco de un espacio universitario en el que su análisis y desarrollo dependían de la disponibilidad física, mental y emocional de cada estudiante, representó una experiencia sensible y reflexiva, gracias a la cual se analizan los objetos de estudio a través de lenguajes como el cuerpo y el teatro.

Además, la experiencia acercó a la población estudiantil a la teoría de autores como Augusto Boal, Paulo Freire, Bertold Brecht, como principales pilares de la base teórica, la cual se vio reflejada en la práctica por medio de dinámicas, escenas y obras de teatro creadas durante las diecisiete sesiones de trabajo que albergaba el curso.

Otro de los objetivos fue convertir el salón de clase en un espacio de confianza, diálogo y humanidad en el que cada miembro disfrutara cada sesión; en otras palabras, cambiar la imagen convencional de un salón de clase que el estudiante visita para recibir información e irse y, por ende, limitar el disfrute de la experiencia de aprendizaje.

Durante las sesiones de trabajo, se desarrollaron diferentes etapas metodológicas para buscar la construcción crítica y preparación corporal para traducir en lenguaje teatral el criterio del colectivo. Dichas etapas se pueden sintetizar de la siguiente manera:

- Investigación de conceptos básicos del teatro relacionados con la vida cotidiana.

- Acercamiento a los autores base en los cuales se apoyó el curso.

- $\quad$ Realización paralela del trabajo lúdico/práctico sobre aprender a jugar al teatro.

- $\quad$ Exposiciones grupales sobre temas de interés.

- Escogencia de temáticas y puesta en escena de estas.

- Presentación abierta al público en el teatro. 
Cada uno de los anteriores puntos (ampliados más adelante) estuvo sustentado en el diálogo entre la teoría y la práctica, ya que, por un lado, se estudiaba la propuesta teatral y, por el otro, se ejecutaba; por lo tanto, comprender el discurso formal por medio de la teatralidad y la corporización de conceptos fue un elemento que se debe destacar como indispensable en el marco de esta propuesta académica, pues su motor principal fue que cada estudiante, independientemente de su carrera, lograra asumir y defender un rol activo propositivo acorde con el criterio y la provocación de las temáticas sociales trabajadas. Se puede resumir la experiencia del curso Teatro del oprimido: una perspectiva práctica del humanismo, como una oportunidad en la cual la población universitaria conoció el teatro desde un libro, un vídeo, una mirada, otro cuerpo, su propio cuerpo.

\section{Diseño metodológico}

Las etapas en las que el curso se fragmentó respondieron no solo a un debido cronograma, sino también a la respuesta que la población meta iba presentando a lo largo de las sesiones. Se puede mencionar que la búsqueda de la participación individual y colectiva fue predominante en el diseño del curso, principalmente porque en esta se encuentran la noción del teatro y el trabajo en equipo.

\section{IEtapa: Conceptualización teatral}

En esta etapa se debió partir de que ninguno de los integrantes del grupo es formado en teatro; por lo tanto, se les acercó por medio de conceptos básicos, como: conflicto, acción, asimetría corporal, comunicación no verbal, puesta en escena y demás. Dichos conceptos no solo se comunicaban desde la práctica, sino también desde la observación de los mismos conceptos en los espacios de la vida cotidiana (la calle, la familia, el salón de clase, la Iglesia), logrando recalcar que la materia prima de la cual el arte teatral se alimenta es el cotidiano de la vida $\mathrm{y}$ de las personas, con sus respectivos comportamientos, lenguajes expresivos y relaciones humanas, materializadas de diversas formas.

\section{Etapa: Acercamiento a autores}

Se lograron trabajar las perspectivas teóricas de Boal, Freire y Brecht como fundamentos base, lo que permitió así ampliar la concepción cultural sobre teatro y educación; se partió, además, de que ambos términos van de la mano y se relacionan intrínsecamente en todos los aspectos definidos en el curso. Por lo tanto, conceptos como educación bancaria, opresión, poder y distanciamiento, fueron estudiados y materializados en situaciones sociales concretas. 


\section{Etapa: Jugar al teatro}

Esta etapa estuvo activa desde la primera sesión hasta la última; sin embargo, adquirió mayor fuerza y conciencia una vez establecidas las bases conceptuales del teatro y de los autores. Se puede entender como una etapa en la que los estudiantes lograron filtrar las fases anteriores y traducirlas en sus cuerpos jugando a hacer teatro.

Este proceso generó la disposición necesaria del colectivo para acercarse a la utilización del cuerpo, de una manera poco convencional; al mismo tiempo, se lograron comprender desde el lenguaje expresivo las posibilidades de comunicación de ideas con que cada estudiante contaba.

\section{Etapa: Exposición de temáticas}

Una vez logradas las dos vertientes más importantes del curso, teoría del discurso y práctica corporal, se asignan y proponen temáticas de interés de los participantes y las participantes, relacionadas con la opresión social y las relaciones de poder. Por medio de subgrupos identificados, según intereses, se abordaron temas, de manera crítica, como machismo, agresión sexual, emociona y física, explotación ambiental, maltrato animal, homofobia, manipulación, en función del concepto humanismo y sus derivados.

Dicha etapa permitió que se generaran espacios de debate, reflexión y, sobretodo, de autoanálisis sobre cada temática planteada.

\section{VEtapa: Teatralizar la vida}

Esta quinta etapa es una de las más importantes y delicadas del proceso, ya que en ella el colectivo comparte, de manera personal y sensible, experiencias vividas en las cuales han sido oprimido por otra persona, situación o sistema; cada estudiante de manera voluntaria expresa sensaciones, descripciones, frustraciones, logros obtenidos a partir de dicho referente de vida.

Se utilizó la metodología oportuna para convertir dichos relatos en necesidad colectiva de denuncia social por medio del cuerpo y de los recursos teatrales, y se logró así la iniciación de un proceso de construcción de material escénico, para traducir la temática, mediante la revaloración del relato original y del empoderamiento de cada grupo en la posición crítica ante el asunto, que de manera democrática se seleccionó. 
Para fortalecer lo anterior, se consideró la noción de democratización planteada por Carlos Taibo (2005): "en el terreno de la política, los movimientos apuestan por el desarrollo de formas de democracia directa, las que se revelan a través de los procesos participativos" (p. 77).

\section{Etapa: Presentación pública}

Se realizó un Teatro Foro con el objetivo de compartir el trabajo e involucrar a la población en general en un proceso que culmina en el momento de comunicar ideas concretas e invitar al público a tomar decisiones y a pensar activamente en las temáticas propuestas. En este espacio final, el grupo de estudiantes metafóricamente alzan su voz y expresan sus posiciones críticas ante un público invitado a debatir las soluciones de dichas problemáticas sociales.

Es aquí donde el objetivo del curso se verbaliza, ya que el desarrollo sensible y crítico buscado logra su empoderamiento en la intencionalidad de la transformación social.

\section{Factores determinantes en el desarrollo de la experiencia}

Todo proceso académico conlleva una serie de elementos que favorecen la experiencia realizada; dichos elementos se pueden ver como vertientes que conducen el camino por recorrer, siguiendo los objetivos. En el caso del proceso de Teatro del oprimido: una perspectiva práctica del humanismo, los factores que colaboraron en su recorrido fueron:

Proceso de deserción: se considera como un elemento fundamental en la consolidación de un grupo de estudiantes realmente interesados en la propuesta académica y, principalmente, en la visualización del participante en lo descrito por el curso. La deserción en todo grupo social es normal, pues filtra a aquellas personas que se disponen a realizar lo propuesto, lo cual es abierto a las modificaciones y a los aportes que se puedan hacer. Se podría decir que los 30 estudiantes que terminaron el proceso académico estuvieron motivados y comprometidos en la defensa práctica del curso.

Pluralidad de intereses: uno de los aspectos interesantes que ofrece el CEG es la recepción de estudiantes de todas las carreras que la UNA ofrece; por lo cual, contar con una población heterogénea en cuanto a carreras, perspectivas y contextos sociales ayuda a enriquecer la práctica teatral y el análisis crítico ante determinados temas de intereses colectivos. 
Corporización: el proceso de redescubrimiento del aparato corporal en función del juego escénico permitió un reconocimiento de las capacidades y limitaciones, tanto sociales como físicas, que la dinámica práctica generaba en integrantes. Además, entender el cuerpo como un medio de denuncia, comunicación y expresión significó en el colectivo una experiencia no convencional de llevar a cabo un curso académico de la universidad.

\section{Resultados obtenidos}

La experiencia facilitó mucho material, tanto intelectual, como expresivo, social y teatral, que superó las expectativas académicas iniciales. A continuación se presenta una síntesis sobre los resultados:

- Consolidación de un grupo de estudiantes comprometidos en un curso del CEG, en el que de manera voluntaria participaran y aportaran durante el proceso del trabajo.

- Abordar el cronograma del curso en su totalidad, lo cual generó nuevas propuestas e inquietudes en el responsable académico, para el recibimiento de próximos grupos de estudiantes.

- Generar un espacio socialmente apropiado para la confianza, en el cual no existió limitación para abordar temas personales como violaciones, acosos, homosexualidad y vicios, y poder compartirlos como colectivo para su análisis, según necesidades del proceso.

- Formación de relaciones interpersonales que superaron la resistencia social de interactuar con otras personas dentro del salón y fuera de este. Inclusive, la inquietud por parte de algunos de formar grupos externos de Teatro del Oprimido, en áreas como Biología y Educación.

- Un mayor bagaje cultural respecto de la concepción popular sobre teatro, al ser culturalmente la idea de que teatro es entretenimiento cómico, como desenvolvimiento universal de dicho arte.

- Necesidad de ampliar el trabajo escénico, al compartirlo con un público expectante, y la generación de la incertidumbre que esto provoca.

- Empoderamiento social, sensibilidad y crítica.

\section{Enseñanzas extraídas}

Dos elementos se pueden mencionar como principales enseñanzas articuladas en función de ciertos autores y del propio proceso humano generado. Una de estas es la auto observación que el académico debe desarrollar cuando se trabaja a partir 
de material humano y las implicaciones que este demanda, como valoración de tiempos individuales y colectivos para la aprehensión de contenidos prácticos.

Se considera este elemento como fundamental para que el responsable no limite los procesos personales y sociales del grupo, supeditados a un cronograma que debe ser flexible y modificable, pues por la naturaleza del curso, este necesita avanzar dependiendo de la disponibilidad y del material generado a partir de los estudiantes.

Una segunda enseñanza brindada por el proceso fue la valoración de un curso, el cual se construye de manera dialógica y horizontal, sin perder de vista el contenido y la formalidad de las premisas que lo fundamentan; sin embargo, se consideran claves la metodología participativa y la creación colectiva como herramientas que aseguran un buen proceso educativo.

\section{Conclusiones}

Un aspecto importante de la experiencia es la necesidad de expresar y buscar alternativas prácticas ante la identificación de problemas sociales y sus causas; dicha necesidad puede llevar el nombre de germen crítico, pues hace reconocer que no hace falta sólo identificar el problema, sino también buscar los mecanismos o las alianzas sociales que se acerquen a la resolución de ciertas opresiones.

Lo anterior permite comprender la posición de Taibo, al estudiar el origen y desarrollo de los movimientos sociales latinoamericanos, ya que apunta sobre las razones políticas y culturales, las cuales despliegan acciones ciudadanas, movilización e ideologías sociales, donde se apela a las redes capitalistas que tejen la exclusión social. Taibo (2007) plantea que en los movimientos sociales se "garantiza en plenitud los derechos de las minorías, sea cual sea la condición" (s.p.). Parte de la defensa de esos derechos se basa principalmente en la identificación de necesidades colectivamente compartidas, lo cual da paso a un lenguaje traductor de la movilización.

Por lo tanto, el curso confirma la necesidad de movilización social y la conciencia generada a partir del encuentro de un lenguaje en común, el teatro y, específicamente, el cuerpo, mediante la conceptualización política de este en procesos de denuncia social.

Augusto Boal (1996) sistematizó una poética artística al apelar a formas distintas de combatir la discriminación opresiva, al crear nuevas formas de comunicación, Él señala que el Teatro del Oprimido, en sus diversas modalidades, es una constante búsqueda de formas de diálogo, formas de teatro que puedan conversar sobre la actividad social, la pedagogía, la psicoterapia y la política. 
Lo anterior permite valorar el papel que desempeña el teatro en estos procesos académicos, pues llega a significar en el bagaje crítico del universitario una opción más para traducir su pensamiento y su voz. El teatro es una alternativa de denuncia social, que involucra activamente a aquellos que participan directa o indirectamente del producto mostrado.

Por otra parte, es importante la transición de conceptos, ocurrida desde el choque conceptual que se presenta al inicio del curso al definir la concepción de teatro, al mismo tiempo que se le asigna el adjetivo de teatro social. Culturalmente, el costarricense promedio identifica la palabra teatro con sinónimos como comedia, cuyo fin se concentra en entretener y hacer reír, como un concepto homogéneo y hasta erróneo del significado del teatro. Dicha postura refleja no solo la limitación cultural, sino también la mercantilización del arte como un elemento disponible para consumir; por lo tanto, ante la redefinición del concepto como punto de partida del proceso, la reacción del estudiantado va dirigida a la duda y, a la vez, a la expectativa de la propuesta académica.

En relación con lo anterior y al ahondar en el proceso de la globalización mercantil de la cultura, forzándola a convertirse en homogenizante y estandarizada, se confirma el desvío del enfoque y la fuente viva de las manifestaciones culturales. Actualmente se impulsa la industria cultural desde el beneficio de accesibilidad global; sin embargo, dicha expansión ilegitima la sensibilidad en los procesos de creación; por lo tanto, es una de las generalidades que se debe considerar en futuros procesos. Mattelart (2003) expone que la humanidad se instala en el monocultivo, se dispone a producir civilización en masas. Por ende, concebir el teatro como un concepto homogenizado desde la perspectiva mercantil, en balance con una masificación cultural y humanitaria, son elementos interesantes a ser articulados en los procesos de experimentación artística en espacios universitarios, pues se evidencian los conceptos hegemónicos que el sistema capitalista reproduce en los distintos ámbitos de la vida, entre ellos: el arte y su abanico de posibilidades.

Dicha pretensión homogeneizadora de la cultura evidencia que un fenómeno como el teatro, sin una concepción diversificada, apuntaría a comprender la vida desde un solo lente y, precisamente, el curso buscó ampliar dicha noción.

Por todo lo anterior, es importante valorar que el desarrollo investigativo y explorativo generado en los participantes por la práctica del curso fortaleció sus objetivos, pues por medio de las técnicas, de los intereses profesionales, del bagaje cultural, del análisis sobre el enfoque globalizante en los procesos culturales 
y políticos del arte y los antecedentes y las ramificaciones de los movimientos sociales en defensa de sus derechos, hicieron que la respuesta de un grupo heterogéneo de estudiantes encontrara como común denominador la necesidad de alternativas profesionales que hagan valer el compromiso social que todos y todas buscaron defender, como resultado de la formación humanista ofrecida por el CEG como educación universitaria; en otras palabras, como fabricación de humanidad. Y el teatro como herramienta educativa sensible ofrece la posibilidad de fabricar humanidad.

Uno de los planteamientos del Teatro del Oprimido es que todos los seres humanos son actores y espectadores, porque todos hacen y observan directa o indirectamente los quehaceres de la vida cotidiana. Por lo tanto, la participación del público como un elemento primordial en el teatro y, especialmente, en la dinámica de esta corriente, representó en los estudiantes un encuentro dialógico importante. Por medio de las propuestas escénicas creadas durante el curso, se logró generar provocaciones en el público y, por ende, un debate de acción que confrontó al estudiantado a interactuar actoralmente con los espectadores. Así se cumplió el objetivo de socializar reflexivamente temas propuestos como burocracia institucional, presión laboral, abuso sexual, bullying y otros más.

La experiencia de convertir en actores y actrices a los estudiantes y las estudiantes, por medio de un acercamiento escénico, representó que el curso simbolizara lo expresado por Boal (2004) en la siguiente cita: "el Teatro del Oprimido es un espejo donde podemos penetrar y si no nos gusta nuestra imagen reflejada en él, podemos transformarla, esculpirla de nuevo según nuestros deseos, porque el acto de transformar es transformador: ¡Al transformarla, nos transformamos a nosotros mismos!” (s.p).

La mayor conclusión de dicha experiencia fue que cada estudiante universitario defendió su condición de actor/espectador de la vida cotidiana, lo cual significa en palabras de Boal (2004) "...un participante activo, creador, dispuesto a intervenir". Esa disposición de hacer, de valorar el compromiso social que como universitario se posee es el aporte principal que el curso facilitó a cada estudiante. 


\section{Referencias}

Boal, A. (1998). Teatro Legislativo. Brasil: Civilización Brasileña.

Boal, A. (2004). Arco Iris del Deseo. España: Alba Editorial.

Gentili, P. (2012). Pedagogía de la igualdad. Buenos Aires: Siglo Veintiuno Editores. Mattelart, A. (2003). La mundialización de la comunicación. Barcelona: Paidós Ediciones.

Morin, E. (2010). Morin, Edgar ¿Hacia el Abismo? Globalización en el Siglo XXI. Barcelona: Paidós Ediciones.

Pineda, M. (2002). Globalización, tecnologías de la información y diversidad cultural. Revista Latina de Comunicación Social. Laboratorio de Tecnologías de la Información y Nuevos Análisis de Comunicación Social. ISSN 1138-5820

Taibo, C. (2007). ¿Qué son los movimientos? Movimientos antiglobalización. México: Editorial Catarata. 